\title{
Effective Diversity Management of Expecting and New Parents
}

\author{
Meredith Wilson \\ Peter Woods, Griffith University, Australia \\ Leang Phal
}

\begin{abstract}
This article reviews the literature relating to the workplace issues of expecting and new parents within the framework of diversity management. Family status is a secondary dimension of diversity, and organisational responses to pregnant workers, new parents and those returning to work have rarely been explored in the context of diversity management. The concepts of diversity, diversity management and the benefits of effective diversity management are explored in relation to new and expecting parents. The issues of working mothers, pregnancy, breastfeeding, discrimination, industry segmentation, organisational commitment and organisational social responsibility in relation to diversity management are discussed. Recommendations are made regarding maternity leave, paternity leave, return to work strategies, flexible work practices, organisational culture and the role of supervisors.
\end{abstract}

Keywords: Diversity Management

$\mathrm{T}$ HE AUSTRALIAN ORGANISATION today competes in an increasingly competitive labour market while attempting to balance worker's calls for greater flexibility with stakeholder calls for greater efficiency. Against this background, this paper explores workplace strategies for pregnant workers; new parents and those returning to work after parental leave within the context of diversity management. The secondary diversity dimension of family status has rarely been explored in relation to diversity management, and this paper recommends a number of strategies in relation to expecting and new parents. A discussion of definitions of diversity and diversity management are examined, followed by an examination of the problems and issues of working mothers and fathers. A range of flexible work arrangements available to organisations in addition to parental leave considerations is explored. Family friendly policies and practices are popular with employees and family advocates, however most studies show, both in Australia and internationally, that employer support is limited to certain industry segments and that they are not accessible to all working parents. By creating a culture where diversity is valued, organisations can ensure high organisational commitment of working parents by implementing family friendly policies and procedures.

\section{Diversity}

Diversity has been defined as the specific characteristics that differentiate one individual from another (De Cieri \& Olekalns, 2001; Dobbs, 1996). Loden $\&$ Rosener (1991) identify diversity in the organisa- tional context as the important dimensions of differences among an organisation's human resources and they classify diversity into two categories. The primary dimension classifies observable characteristics such as gender, age, ethnicity, race, physical and mental abilities and sexual orientation. The secondary dimension includes factors that cannot be observed such as education, physical abilities or qualities, religious beliefs and family status such as pregnant workers, new parents and those returning to work after parental leave.

\section{Diversity Management}

Cox (1993) defines diversity management as the development and implementation of organisational systems and practices to manage people so that potential advantages of diversity are maximised while its potential disadvantages are minimised to the lowest level possible. Kramar (1998) identifies four notions that incorporate the concept of diversity management. They are managing the differences and similarities of individuals; specification of the all of the dimensions of diversity including primary and secondary; management of a combination and mixture of differences and similarities and managing 'inclusion' rather than assimilating different groups to a dominant organisational culture. Diversity management is an approach explicitly concerned with the integration of people management issues with business issues and the development of workplace culture that acknowledges the necessity to manage the similarities and differences between contributors to the enterprise (Kramar, 1998). The

INTERNATIONAL JOURNAL OF DIVERSITY IN ORGANISATIONS, COMMUNITIES AND NATIONS, VOLUME 5, 2005/2006 http://www.Diversity-Journal.com, ISSN 1447-9532 (print), 1447-9583 (online)

(C) Common Ground, Meredith Wilson, Peter Woods, Leang Phal, All Rights Reserved, Permissions: cg-support@commongroundpublishing.com 

VOLUME 5

focus of this paper will be explore how organisations can employ diversity management practices to maximise the participation, inclusion and integration of pregnant workers, new parents and those returning to work after parental leave.

\section{Benefits of Effective Diversity Management}

Effectively managing a diverse workforce has been proposed to produce a number of benefits to organisations (Carr-Ruffino, 1999). The six benefits that have been proposed include attracting and retaining the best human talent (Hicks-Clarke \& Iles, 2002); an increase in organisational flexibility (Cox \& Blake, 1991); increasing and sustaining market share amongst diverse market groups (Beale \& Cox, 1997); greater innovation and more creative problem solving through input from diverse individuals (Cox \& Blake, 1991) and an increase in workplace productivity (Hayles \& Mendez, 1997). Effective diversity management has also been seen as a socially responsible practice within organisations (Cox \& Blake, 1991). De Cieri \& Olekalns (2001) have argued that organisations that fail to effectively manage their diverse workforce may experience unnecessary employee turnover and absenteeism among minority groups. This especially applies to new or expecting parents who leave organisations as they are unable to balance the competing demands of work and family. Other indirect costs of poor management of diversity include frequent recruitment procedures, inability to recruit the best staff and difficulty attracting customers from diverse backgrounds to the business (De Cieri \& Olekalns, 2001). Organisations may benefit, therefore, through maximising the participation, inclusion and integration of pregnant workers, new parents and those returning to work after parental leave.

\section{Working Mothers}

With the rising participation rate of women in the Australian workforce, there is also a concurrent rise in the number of new mothers in the workforce (ABS, 2002). Upward trends in childlessness, also seen in other developed countries, have been linked to women's increased affiliation with careers and higher labour force participation (ABS, 2002). Australia has similar employment patterns to those found in the US, where despite the rapid increase in employed mothers, parents are more likely to negotiate on an individual basis in an effort to integrate their work and family lives (Haas, Hwang \& Russell, 2000). The introduction of workplace based employment agreements called Enterprise Bargaining Agreements [EBA] in Australia has been heralded by the federal government as promoting flexibility for parents, however the realisation of this hope into better management practices is unclear (Strachan, 2003). Overall, Trade Unions have been active supporters of employed parents through the inclusion of family friendly policies in workplace negations with employers (Haas, et al, 2000). This is in contrast to a perceived reluctance of Australian organisations to implement overall diversity management strategies (Hay, 2001).

\section{Discrimination}

Although significant progress against systemic discrimination towards women in the workplace has occurred in Australia, it is their responsibilities as primary bearers and carers of children that continue to disadvantage women in the areas of remuneration, selection and promotion (HREOC, 2002; Friedman, 2001). While pregnant employees are covered under anti-discrimination legislation, the issues of working parents are not usually associated with anti-discrimination provisions (Kramar, 2001). The large number of women in part-time and casual positions (ABS, 2000) means they are combating lower income levels, perceived lower commitment and therefore less opportunity for promotion to positions of power or influence. Often, this is combined with reduced access to, and knowledge of, benefits, conditions, family friendly policies and procedures. For some feminist writers these difficulties are analysed along dimensions of power and powerlessness (Strachan, 2003; Bacchi, 2000), highlighting the historically entrenched imbalance of power both within and outside of the workplace. Junor (2000) discusses the gendered divide of full-time and part-time work and its implications for replacing the family wage. Organisational diversity management initiatives oriented towards expecting and new parents, therefore, must include guarantees of equality in pay, provision of equal opportunities and suitable work-life balance policies to avoid the organisation reinforcing gender inequality in the workplace.

\section{Pregnancy}

Thompson \& Francesco state that $85 \%$ of women have children during their working years (1996). Thus organisations cannot expect to have women in the workforce without having to deal with pregnant employees. Under Australian Anti-Discrimination legislation, both federal and state, there is a legal obligation for organisations not to treat pregnant employees differently from other employees. As it is common for pregnant employees to work well into their last trimester (Thompson \& Francesco, 1996) organisations may need to provide flexibility in job requirements, such as alternate duties, similar to an 
injured employee returning to work. Ideally this would occur in consultation with the employee. Some consideration may need to be given to providing uniforms for pregnant employees where needed. Some flexibility in hours or work if required will be appreciated by families who are expecting a child, and this provision has the potential to positively impact staff loyalty and psychological commitment to the organisation. The myths about pregnant women's lack of commitment to paid employment are not supported by available data (Lyness, Thompson, Francesco \& Judiesch, 1999). Studies in the US found that accommodative employers had reduced absenteeism rates during pregnancy, more positive job satisfaction of employees and that employees worked later into their pregnancy (Lyness et. al., 1999). It was also shown to increase the rate of returning to work of employees after parental leave (Lyness et. al., 1999). Pregnancy and the issues around managing pregnant employees could be included in diversity training within organisations to facilitate a broader appreciation for the needs of pregnant employees. Organisations can also assist through working towards a responsive organisational culture exemplified by women and managers comfortably being able to advise and negotiate leave. This would benefit both the employee and also aid in organisational planning.

\section{Maternity and Paternity Leave}

Maternity leave is statutorily provided for in Australia, however the length of time, whether it is paid or unpaid, and the option to take half-pay/ double time are all issues negotiated at the organisational level. An Equal Opportunity for Women in the Workplace (EOWA) survey (2001) found that $88 \%$ of organisations surveyed provided paid maternity leave, most commonly of 5 to 6 weeks duration. It also showed that industry segmentation greatly impacted the rate and length of paid maternity leave. Only $15 \%$ of organisations provided paid paternity leave.

Effective diversity management practices can include access to parental leave for working fathers, with flexible options for parents eschewing the traditional male breadwinner and female primary carer roles. Traditionally, males in the workforce had a support system at home fulfilling family responsibilities. With an increase in dual career families, family responsibilities have begun to overlap with work responsibilities (Ezra \& Deckman, 1996). Parents benefit from being able to utilise leave for family or child emergencies, such as carer's leave. Fathers also benefit from equal access rights to parental leave and the flexibility to take paternity leave if desired. The importance of fathering has been increasingly recog- nised with concurrent bi-directional trends of increasing prevalence of single parent families and the changing, more personally involved role of fathers in Australian families (Eveline, 2001). Managing a diverse workforce means ensuring equality for working parents whether male or female. It also requires allowance for differing families including blended families, adoption and families other than the traditional model (Roberts, 2000; Eveline, 2001; Ezra \& Deckman, 1996).

\section{Return to Work}

Within the context of effective diversity management, family friendly policies and procedures must go beyond the basic pregnancy and maternity leave provisions towards a practical recognition of the challenges of balancing parenting and work. Parent's return to work is a crucial time for organisations to provide support. Returning to the same job after maternity leave allows women employees and organisations to collect on 'investments' made in training and person-job fit (Klerman \& Leibowitz, 1999, p.146). McIntyre, Pisaniello, Gun, Sanders \& Frith (2002) examined the issue of combining breastfeeding and paid employment. While Australia has one of the highest starting rates of breastfeeding infants in the world, it also has one of the earliest and most dramatic drop-off rates (ABS, 2000). One of the main reasons cited for this is the return to paid work of mothers following maternity leave. A social and health issue for the nation is thus to encourage the combining of breastfeeding with the return to work of mothers. Employers can offer support to mothers to continue breastfeeding by providing a number of practices and support measures including flexible leave arrangements, telecommuting arrangements where possible, and privacy and storage facilities for mothers who express milk for later feeding. The benefits to organisations could include the instance of fewer and less severe illnesses in infants who are breastfed and therefore lower absenteeism rates for parents of young children (Haider, Jacknowitz \& Schoeni, 2003). Another factor increasing absenteeism rates for parents of young children is the availability of quality and affordable childcare. Organisations can assist through the provision of on-site childcare, the recognition that flexibility in hours may be required for those parents struggling with childcare needs and the provision of childcare sourcing facilities for employees (Roberts, 2000; Klerman \& Leibowitz, 1999; Thompson \& Francesco, 1996; Ezra \& Deckman, 1996).

\section{Flexible Work Practices}

Flexible work practices represent a range of options available to organisations in relation to the redesign 

VOLUME 5

of the length of the work period in which work is completed or flexitime, the location at which work will be performed or flexi place, and the nature of how the work will be completed. These may include working from home and telecommuting. Flexitime may range from term time work (where school holidays are spent caring for children), to school friendly working hours such as $9 \mathrm{am}$ to $3 \mathrm{pm}$. It also incorporates the more common accrual of overtime to be taken when needed and the practice of working hours being condensed into fewer, though longer, days. Job sharing and part-time work are also commonly used flexible working arrangements. All of these allow parents to be available to meet any family responsibilities when needed. The absence of family friendly policies and procedures can intensify employee tension and stress leading to "increased absenteeism, tardiness, job burnout, lower organisational commitment, reduced motivation and ultimately decreased performance" (Roberts, 2000, p.52). By introducing flexible work practices, the flexibility of the organisation can be enhanced as one of the six key benefits of diversity outlined earlier. Ezra \& Deckman (1996) argue that organisations and Human Resources will need to analyse their approach to recruitment and retention and their expectations of employees at work to accommodate modern expectations of working parents.

\section{Organisational Culture}

A supportive organisational culture is very important in realising the benefits of effective diversity management. Organisations benefit through the promotion of attitudes that value difference and where effective and sustainable family friendly policies and practices are offered in an environment where employees are not penalised, however indirectly, for utilising the options available. A Penn State University study (2002) found that in professional occupations "substantial non-work commitments are neither expected nor tolerated...” and that "...discrimination against parenting is implicit in many career ladders, occupations, and employing institutions". Cross (2000) supports this in the many examples she cites where assumptions were made that mothers could not or would not commit to the organisation. Lyness, Thompson, Francesco \& Judiesch (1999) found that many women believe that once they became a mother they were automatically perceived to be less committed to their career. They also found that women whose organisations were perceived to be supportive of work-family balance were more committed to their organisations and planned to return to work more quickly after childbirth than women who perceived less supportive organisational cultures (Lyness, et al, 1999).
The reality for most organisations is that most 'family' friendly policies and practices are seen as women's benefits and whilst available, are not provided within a supportive environment (Lee \& Duxbury, 1998; Haas, et al, 2000). The policies governing the use of 'time-off' benefits, including flexitime, sick leave and parental leave, need to allow accessibility and flexibility of use for the benefits to be of true value to parents, (Roberts, 2000). Broad organisational understanding and acceptance of these provisions and of the issues affecting working parents is an important part of a supportive organisational culture, and this can be enhanced by including these issues in effective diversity training.

\section{Role of Supervisors}

Supportive supervisors and a supportive organisational culture are important to the accessibility of family friendly policies and practices in any organisation (Lee \& Duxbury, 1998). Ezra \& Deckman (1996) argue that unless an employee's immediate supervisor is supportive of family friendly policies the organisation's policies and procedures will not be used adequately. Organisations therefore need to support the introduction of family friendly policies and procedures through selection, promotion and training to management to ensure adequate and full implementation in the organisation and freedom to access the available conditions and benefits (Lee \& Duxbury, 1998).

\section{Industry-Related Issues}

Family friendly policies and practices are popular with employees and family advocates, however most studies show, both in Australia and internationally, that employer support is limited to certain industry segments and that they are not accessible to all working parents (Friedman, 2001; ABS, 2000; Frone \& Yardley, 1996; HREOC, 2002; Anonymous, 2002; Lee \& Duxbury, 1998; Klerman \& Leibowitz, 1999; Thompson \& Francesco, 1996; Taniguchi, 2002). Factors impacting accessibility include the industry sector, the size of the organisation, regional variances, specialisation of the position or role and the working arrangements (Friedman, 2001). Strachan (2003) argues that "male dominated industries focus on more recruitment and retention of women" rather than on flexible work policies and procedures. Most small businesses lack the resources and expertise to provide such conditions of employment and benefits (Roberts, 2000).

\section{Organisational Social Responsibility}

Within the context of the social responsibility of organisations, improved organisational practices with 
regards to working parents can have wider effects on society. Infants and mothers benefit from their mother's full-time care during maternity leave periods (Klerman \& Leibowitz, 1999) and greater parental involvement with children is usually perceived as having a positive wider social impact. Organisational practices can positively influence society through the transfer of education and exposure to different practices and ideals of employees in the workplace, to their life outside the workplace. Conversely, societal changes reflected in evolving parental roles, the current debate on the impact of absent fathers and changing families, a diverse population and globalisation will impact on the workplace as societal norms change. Eveline critiques current policies as "rarely designed to remove the double burden from women, much less to persuade men to treat child nurture as central to their lives" (Eveline, 2001, p.17). It is only with combined societal change, supported by government policies and practices, that true and lasting organisational change is possible (Cross, 2000, p.100; HREOC, 2002; Kramar, 2001).

\section{Conclusion}

In order to move from the current pattern of individual negotiation in dealing with the challenges of integrating work and family lives, working mothers and fathers require an organisational or enterprise based approach to provide them with the flexibility they require. Organisations that adopt a diversity management approach to dealing with the issues of pregnant and new parents may benefit from the flexibility and more efficient productivity that diversity initiatives engender within the organisation. Furthermore, by providing more opportunities for pregnant and new parent workers, the organisation may benefit by retaining good staff and thus reducing costly staff turnover. By retaining pregnant and new parents, the organisation broadens the diversity of workers within its ranks, which has a positive impact on in- novation, creative problem solving and the ability to relate to broader sections of the marketplace. Through confronting discrimination and creating positive conditions for breastfeeding and parental involvement with children, organisations contribute to the overall wellbeing of society.

To achieve these benefits, organisations need to provide flexible, equitable and specific parental leave. Provision or sourcing of childcare and flexibility of work hours to allow parents to utilise childcare provisions may facilitate the return to work of new parents. Facilities and work flexibility for breastfeeding mothers is also important in catering for mothers returning to work. A range of flexible work practices such as flexi-time, flexi-place, condensing work hours, telecommuting, job sharing and part-time work can facilitate the recruitment and retention of parents returning to work. The feasibility of these provisions, however, depends on the industry and size of the organisation, and the nature and specialisation of the work role. The common attitudes of particular industries towards women, however, are also a factor in the management of the needs of pregnant and new parent workers. Related to this, a supportive organisational culture where diversity is valued, leave provisions are compassionately administered and the needs of pregnant and new parent workers are understood is an essential part of effective diversity management. The appropriate selection, training and promotion or supervisors and useful training regarding diversity initiatives are required to properly implement effective diversity management of new parents.

Effective diversity management of pregnant workers and new parents holds great promise for organisations and for society generally. The Australian trends of rising workforce participation of mothers and the changing parental demands on fathers makes the diversity management initiatives outlined here imperative for the effective management the Australian worker and the Australian workplace.

\section{References}

Albrecht, M.H. (2001). International Human Resource Management: managing diversity in the workplace. Oxford: Blackwell Business.

Anonymous (2002). Balancing work and family not easy for women faculty. Academe, 88 (4).

Australian Bureau of Statistics. (2000). Working Arrangements. Canberra: Australian Government Publishing Service.

Australian Bureau of Statistics. (2002). Australian Social Trends 2002 - Family Formation. www.abs.gov.au/ausstats/

Bacchi, C. (2000). The Seesaw Effect: Down goes Affirmative Action, Up comes Workplace Diversity. Journal of Interdisciplinary Gender Studies, 5 (2), p.64.

Beale, R.L \& Cox, T. Jr. (1997). Developing Competency to Manage Diversity: Readings, Cases and Activities. San Francisco: Berrett-Koehler Publishers Inc.

Carr-Ruffino, N. (1993). The Promotable Woman (2nd ed.). Belmont: Wadsworth Publishing Company.

Conway, N. \& Briner, R.B. (2002). Full-Time versus Part-Time Employees: Understanding the Links between Work Status, the Psychological Contract, and Attitudes, Journal of Vocational Behavior, 61, p.279.

Cox, T. Jr. (1993). Cultural Diversity in Organisations: Theory, Research and Practice. San Francisco: Berrett-Koehler Publishers 

VOLUME 5

Cox, T., Jr. \& Blake, S. (1991). Managing Cultural Diversity: Implications for Organisational Effectiveness. The Executive, $5(3), 45-55$.

Cross, E.Y. (2000). Managing Diversity - the courage to lead. Wesport, CN: Quorom.

Council for Equal Opportunity in Employment. (1990). Women, Work and the Future, 112 Studies from Major Australian Companies, Book 10. Melbourne: Council for Equal Opportunity in Employment.

Department of Employment and Workplace Relations. (2002). Workplace Diversity Strategy: 1999-2002. www.dewr.gov.au

De Cieri, H \& Olekalns, M. (2001). Workplace Diversity in Australia: Challenges and Strategies for Diversity Management. Monash University: Faculty of Business and Economics, 2001 (9), 1-15

Dobbs, M.F. (1996). Managing Diversity: Lessons from Private Sector. Public Personnel Management, 25 (31), 351-370.

Equal Opportunity for Women in the Workplace Agency. (2001). Survey - Paid Maternity and Paternity Leave. www.eowa.gov.au/Resource_Centre.asp

Esty, K, Griffin, R. \& Schorr Hirsch, M. (1995). Workplace Diversity. Holbrook: Adams Media Corporation.

Eveline, J. (2001). Whither the 'New Father'? Male Managers and Early Child Care in Australia and Sweden. Journal of Interdisciplinary Gender Studies, 6 (1), 3.

Ezra, M, \& Deckman, M. (1996). Balancing work and family responsibilities: Flex time and childcare in the federal government. Public Administration Review, 56 (2), 174.

Friedman, D. (2001) Employer supports for parents with young children. The Future of Children, 11 (1), 62.

Frone, M., \& Yardley, J.K. (1996) Workplace family-supportive programmes: Predictors of employed parents' importance ratings. Journal of Occupational and Organizational Psychology, 69 (4), 351.

Haas, L. Hwang, P. \& Russell, G. Eds. (2000). Organizational Change and Gender Equity: International perspectives on Fathers and Mothers in the Workplace. Thousand Oaks, CA: Sage Publication Inc.

Haider, S.J., Jacknowitz, A. \& Schoeni, R.F. (2003) Welfare work requirements and child well-being: Evidence from the effects on breastfeeding. Demography, 40 (3), 479-497.

Harvey, C., Allard, M. (2002). Understanding and Managing Diversity: Readings, Cases and Exercises. Upper Saddle River, NJ: Prentice Hall.

Hay, C (2001). Report Card: AHRI's Workforce Diversity Management Survey 2001, A joint project by the Australian Human Resource Institute and the Commonwealth Department of Immigration and Multicultural and Indigenous Affairs, in conjuction with Consulting Partners Australia

Hayles, R \& Mendez, R.A.(1997). The Diversity Directive, New York: McGraw-Hill

Hicks-Clarke, D \& Iles, P.(2000). Climate for Diversity and its Effects on Career and Organisational Attitudes and Perceptions. Personnel Review, 29 (3), 324-345.

Human Rights and Equal Opportunity Commission. (2002). Valuing Parenthood: Options for Paid Maternity Leave Interim Paper 2002. www.hreoc.gov.au/sex_discrimination/pml/

Jacobsen, D.I. (2000). Managing increased part-time: does part-time work imply part-time commitment, Managing Service Quality, 10 (3), 187.

Junor, A. (2000). Permanent Part-Time Work: Rewriting the Family Wage Settlement, Journal of Interdisciplinary Gender Studies, 5 (2), 94.

Klerman, J.A. \& Leibowitz, A. (1999). Job continuity among new mothers. Demography, 36 (2), 145.

Kramar, R. (1998). Managing Diversity: Beyond Affirmative Action in Australia. Women in Management Review, 13(4), 133-142.

Kramer, R. (2001). Managing diversity: challenges and future directions. in Weisner, R, \& Millett, B. (Eds.) Management and organisational behaviour: contemporary challenges and future directions. Brisbane: Wiley.

Lee, C. \& Duxbury, L. (1998). Employed Parents' Support from Partners, Employers and Friends. The Journal of Social Psychology, 138 (3), 303.

Loden, M \& Rosener, J.B. (1991). Workforce America!: Managing Employee Diversity as a Vital Resource, Homewood, Illinois: Irwin

Lyness, K., Thompson, C., Francesco, A.M. \& Judiesch, M. (1999). Work and Pregnancy: Individual Organizational factors including organizational commitment, timing of maternity leave and return to work. Sex Roles, 41(7/8), 485.

McIntyre, E., Pisaniello, D., Gun, R., Sanders, C. \& Frith, D. (2002). Balancing breastfeeding and paid employment: a project targeting employers, women and workplaces. Health Promotion International, 17 (3), 215.

Pennsylvania University (2002). Faculty and Families Mapping Project. http://lsir.la.psu.edu/workfam/prelimresults.htm

Public Service and Merit Protection Commission. (2001) Guidelines on Workplace Diversity. Working Together (2). Canberra: Ausinfo.

Roberts, G. (2000). An inventory of family-friendly benefit practices in small New Jersey local governments. Review of Public Personnel Administration, 20 (2), 50.

Simons, G.F., Vazquez, C. \& Harris, P.R. (1993). Transcultural Leadership: Empowering the Diverse Workforce. Houston: Gulf Publishing Company.

Strachan, G. (2003). Affirmative Action or Managing Diversity - What is the future of Equal Opportunity Policies in Organisations? Brisbane: Griffith University.

Taniguchi, H. (2002). Determinants of women's entry into self-employment. Social Science Quarterly, 83 (3), 875.

Thompson, C. \& Francesco, A. (1996). Valuing Diversity: the case of pregnant working women in the United States. Equal Opportunities International, 15 (4), 1.

Zemke, R., Raines, C. \& Filipczak, B. (2000). Generations at Work. New York: AMACOM. 


\section{About the Authors}

Peter Woods

Peter Woods lectures in Diversity Management at Griffith University, Brisbane, Australia. He has successfully managed diverse workforces in government, private and not-for-profit organisations. He was instrumental in establishing multicultural training and multicultural community service organisations in Brisbane. His research interests include cross-cultural management, diversity management and management education. 